OPEN ACCESS

Edited by:

Shang-Tian Yang, The Ohio State University,

United States

Reviewed by: Luis H. Reyes,

University of Los Andes, Colombia Xiaoping Bao,

Purdue University, United States

*Correspondence: Xiaoguang Liu mliu@uab.edu

${ }^{t}$ These authors have contributed equally to this work

Specialty section:

This article was submitted to Biochemical Engineering, a section of the journal

Frontiers in Chemical Engineering

Received: 07 December 2021 Accepted: 10 January 2022

Published: 28 January 2022

Citation:

Guan J-S, Chen K, Si Y, Kim T, Zhou Z, Kim S, Zhou L and Liu X (2022) Process Improvement of AdenoAssociated Virus Production. Front. Chem. Eng. 4:830421. doi: 10.3389/fceng.2022.830421

\section{Process Improvement of Adeno-Associated Virus Production}

\author{
Jia-Shiung Guan ${ }^{1 t}$, Kai Chen ${ }^{2 \dagger}$, Yingnan $\mathrm{Si}^{2}$, Taehyun Kim ${ }^{1}$, Zhuoxin Zhou ${ }^{2}$, Seulhee Kim ${ }^{2}$, \\ Lufang Zhou ${ }^{1}$ and Xiaoguang Liu ${ }^{2 *}$
}

${ }^{1}$ Department of Medicine, University of Alabama at Birmingham, Birmingham, AL, United States, ${ }^{2}$ Department of Biomedical Engineering, University of Alabama at Birmingham (UAB), Birmingham, AL, United States

Adeno-associated viruses (AAVs) have been well characterized and used to deliver therapeutic genes for diseases treatment in clinics and basic research. This study used the triple transient transfection of AAV-DJ/8 as a model expression system to develop and optimize the laboratory production of AAV for research and pre-clinical applications. Specifically, various production parameters, including host cell, transfection reagent, cell density, ratio of plasmid DNA and cells, gene size, and production mode, were tested to determine the optimal process. Our results showed that the adherent production using HEK 293AAV with calcium transfection generated the highest volumetric productivity of $7.86 \times 10^{9} \mathrm{gc} / \mathrm{ml}$. The optimal suspensive production using HEK 293F had best AAV productivity of $5.78 \times 10^{9} \mathrm{gc} / \mathrm{ml}$ in serum-free medium under transfection conditions of transfection density of $0.4 \times 10^{6} \mathrm{cells} / \mathrm{ml}$, plasmid DNA:cells ratio of $1.6 \mu \mathrm{g}: 10^{6}$ cells and synthesized cationic liposomes as transfection reagent. The similar AAV productivity was confirmed at scales of 30-450 $\mathrm{ml}$ in shaker and/or spinner flasks. The in vitro transfection and in vivo infection efficiency of the harvested AAV-DJ/8 carrying luciferase reporter gene was confirmed using cell line and xenograft mouse model, respectively. The minimal or low purification recovery rate of AAV-DJ/8 in ion-exchange chromatography column and affinity column was observed in this study. In summary, we developed and optimized a scalable suspensive production of AAV to support the large-scale preclinical animal studies in research laboratories.

Keywords: AAV, scalable bioproduction, adherent, suspensive, validation

\section{INTRODUCTION}

Adeno-associated virus (AAV) is a small $(20 \mathrm{~nm})$, replication-defective, non-pathogenic parvovirus. The single-stranded DNA (ssDNA) genome with maximal size of $4.8 \mathrm{~kb}$ is encapsidated in nonenveloped capsid (Blessing et al., 2019). Hundreds of serotypes and variants have been isolated and characterized, which can infect both dividing and non-dividing cells of different tissues in human and other animals (Crosson et al., 2018). The chimeric AAV, such as AAV-DJ, has been constructed via capsid evolution of AAV2, 8 and 9 by Kay (Büning and Srivastava, 2019), Samulski (Li et al., 2008) and Schaffer (Koerber et al., 2008) Labs to deliver therapeutic gene to multiple cell types (El Andari and Grimm, 2021).

$\mathrm{AAV}$ has great potential as gene delivery vehicle due to the multiple advantages such as minimal immunogenicity, long-term transgene expression, no adverse events reported in clinics, high stability, and broad range of cell types to infect (Blessing et al., 2019; Hacker et al., 2020). European Medicines Agency (EMA) approved the first AAV-based gene therapy in 2012 to treat 
lipoprotein lipase deficiency (Ledley et al., 2014; van der Loo and Wright, 2016) and United States Food and Drug Administration (FDA) approved Luxturna in 2017 and Zolgensma in 2019 to treat rare inherited blindness and spinal muscular atrophy, respectively. There are more than 300 ongoing clinical studies to treat a wide variety of diseases or disorders, such as Alzheimer, Parkinson, cystic fibrosis, hemophilia B, HIV infection, Leber's congenital amaurosis, arthritis, and cancers (Carter, 2005; Urabe et al., 2006; Chahal et al., 2014; Mietzsch et al., 2014). In addition to clinical applications, AAV is also an important research tool which can deliver reporter genes, CRISPR endonuclease or other genes for fundamental studies (Senís et al., 2014; Crosson et al., 2018).

Because of the broad applications of AAV in basic research and pre-clinical translational study, it is highly desired to develop a robust, scalable and Good Lab Practice (GLP) bioproduction process of AAV vector. Literature has reported multiple AAV production procedures using adherent and suspensive cultures. For example, Grieger et al. have developed a polyethylenimine (PEI)-facilitated three-plasmid transfection protocol by evaluating four ratios of helper, capsid and expression plasmids, two transfection densities and three host cell passage numbers, which generated volumetric productivity of $1 \times 10^{9}-3.3 \times 10^{10}$ vector genome (vg)/mL of AAV (serotypes 1-6, 8, and 9) (Grieger et al., 2016). Blessing et al. reported AAV2/9 productivity of $2 \times 10^{8} \mathrm{vg} / \mathrm{ml}$ in PEI-mediated three-plasmid transfection of suspensive HEK 293 culture (Blessing et al., 2019). Zhao et al. reported an AAV productivity of $3 \times 10^{11} \mathrm{vg} / \mathrm{ml}$ of HEK 293T suspensive culture with PEI transfection (Zhao et al., 2020). In addition, calcium and lipofection have been used to deliver plasmids for adherent AAV production (Negrini et al., 2020). A developed dynamic mathematic model has indicated that the coordination between ssDNA replication and capsid synthesis is a key parameter to produce full capsid AAV (Nguyen et al., 2021). Despite these achievements, the low robustness of production process, high variation of titer and productivity and low biological activity of end product remain the major challenges in AAV production in research laboratory (Wright, 2008; Nguyen et al., 2021).

The objective of this study was to develop and optimize a scalable high-yield production process. Although both adherent and suspensive operation modes were evaluated and compared, we use suspensive production as model system to perform the process development. Various parameters such as host cell, transfection reagent, transfection cell density, plasmid DNA amount, insert gene size, and scalability were investigated to determine the optimal production process. The in vitro transfection and in vivo infection of produced AAV were confirmed using cancer cell line and xenograft mouse model. In addition to production, the purification methods were briefly evaluated but further development is needed. The results obtained in this study could benefit the in-house threeplasmid transient expression of AAV.

\section{MATERIALS AND METHODS}

\subsection{Plasmids for Adeno-Associated Viruses Vectors}

The AAV-DJ/8 Helper Free Promoterless Expression System (Cell Biolabs, San Diego, CA, United States) was applied to construct AAV vector. The pAAV-cfos-NLuc-ACC plasmid (unpublished) was constructed by Professor Zhou Lab (UAB, United States). The blue luminescence-emitting Nanoluciferase (NLuc) reporter gene cloned from pNL-CMV-NLuc (Promega $\#$ N1091) and synthesized ACC genes (unpublished), total of $\sim 3.9 \mathrm{~kb}$, were inserted into the pAAV-MCS vector (Cell Biolabs). The plasmid pAAV-CMV-eYFP was constructed by cloning CMV promoter cloned from pcDNA3.1-PsChR2-eYFP (Addgene \#69057) (Govorunova et al., 2013; Ernst et al., 2019) and eYFP reporter gene from pcDNA3.1-PsChR2-eYFP, totoal of $1.1 \mathrm{~kb}$, into the pAAV-MCS. The PCR primers are NLuc-forward: 5' - ACTCACTATAGGGAGACCCACACCATGGTCTTCACA CTCG-3', NLuc-reverse: $5^{\prime}$ - TGCCTGATCCCGCCAGAATGC GTTCGCAC-3', eYFP forward: 5'-GGTAGTAGCAATGCT AGTGAGCAAGGGC-3' ${ }^{\prime}$, and eYFP reverse: $5^{\prime}$-ACCTTCGAA CCGCGGGCCCTCTAGATTACTTGTACAGCTCGTCC-3'. The pHelper plasmid and pAAV-DJ/8 Rep-Cap plasmid (Cell Biolabs) were used to produce AAV-DJ8 serotype.

\subsection{Cell Lines, Media, and Culture}

The embryonic human kidney (HEK) 293AAV cell line (Cell Biolabs, \#AAV-100), which was cloned and selected from parental 293 cell line (transformed with human adenovirus type 5 DNA), was used to produce AAV in adherent culture. The HEK 293F cell line (Gibco, Buffalo, NY, United States) that was adapted to serum-free medium was used to produce AAV in suspensive culture. The human triple-negative breast cancer (TNBC) cell line MDA-MB-468 (GenTarget, San Diego, CA, United States) was used to test the in vitro transfection capability of AAV and was also used to establish the tumor xenograft animal model to validate the in vivo infection.

All basal media, nutrient supplements and other reagents used in this study were purchased from Thermo Fisher Scientific (Waltham, MA, United States) or Gibco (Grand Island, NY, United States) unless otherwise specified. The HEK 293AAV cells were cultivated in DMEM (high glucose) supplemented with $10 \%$ fetal bovine serum (FBS, v/v), 0.1 mM MEM Non-Essential Amino Acids (NEAA), $2 \mathrm{mM}$ L-glutamine, and $100 \mathrm{IU}$ penicillin and $100 \mu \mathrm{g} / \mathrm{ml}$ streptomycin (i.e., 1\% Pen-Strep) in T75 flasks. The HEK $293 \mathrm{~F}$ cells were maintained in chemically defined (CD) FreeStyle 293 Expression Medium (Gibco) supplemented with $4 \mathrm{mM}$ GlutaMAX in 125 or $250-\mathrm{ml}$ shaker flasks on an orbital shaker at $135 \mathrm{rpm}$. The TNBC MDA-MB-468 cells were maintained in DMEM/F12 medium supplemented with $4 \mathrm{~g} / \mathrm{L}$ glucose, $4 \mathrm{mM}$ L-glutamine, $10 \% \mathrm{FBS}(\mathrm{v} / \mathrm{v})$ and $1 \%$ $\mathrm{P} / \mathrm{S}$ in T-flasks. All the cell cultures were incubated in a humidified incubator (Caron, Marietta, $\mathrm{OH}$ ) with set points of $37^{\circ} \mathrm{C}$ and $5 \% \mathrm{CO}_{2}$. 


\subsection{Adeno-Associated Viruses Production Using Adherent Culture}

The adherent AAV production was performed in $150-\mathrm{mm}$ petri dish. Specifically, the $30 \mathrm{ml}$ of complete DMEM medium (same formulation as seed culture) was seeded with HEK 293AAV at viable cell density (VCD) of $0.1 \times 10^{6}$ cells $/ \mathrm{ml}$. When the confluence reached 95\%, spent medium was removed and replaced with fresh complete medium. The cells were transfected with pAAV-cfos-NLuc-ACC, pHelper, and pAAV$\mathrm{DJ} / 8$ Rep-Cap plasmids with transfection reagent of $25 \mathrm{mM}$ of $\mathrm{Ca}^{2+}$, lipofectamine 3,000 (Gibco), or liposomes synthesized in house. 1) Calcium transfection: The $0.33 \mathrm{ml}$ of $2.5 \mathrm{M} \mathrm{CaCl}_{2}, 30 \mu \mathrm{g}$ of each plasmid (total of $120 \mu \mathrm{g}$ ), and $0.1 \mu \mathrm{M}$ of TE buffer were mixed to reach final volume of $1.5 \mathrm{ml}$. The $\mathrm{Ca}^{2+} / \mathrm{DNA}$ mixture was added to $1.5 \mathrm{ml}$ of $2 \mathrm{X}$ HBS buffer slowly and dropwise to make $3 \mathrm{ml}$ of $\mathrm{Ca}^{2+} / \mathrm{DNA} / \mathrm{HBS}$ mixture, which was added to the 30-ml HEK 293AAV culture. The transfected cells were incubated for $4-6 \mathrm{~h}$, followed with medium exchange and incubation for 48-60 h, and harvested for AAV lysis. 2) Lipofectamine transfection: $10 \mu \mathrm{g}$ of each plasmid (total of $30 \mu \mathrm{g}$ ) and $60 \mu \mathrm{L}$ of $\mathrm{P} 3000$ reagent were added into $300 \mu \mathrm{L}$ of Opti-MEM medium to prepare the DNA-P3000 mixture. The $45 \mu \mathrm{L}$ of Lipofectamine 3,000 was added into $300 \mu \mathrm{L}$ of OptiMEM medium to prepare Lipofectamine 3,000 mixture. The 600$\mu \mathrm{L}$ complete DNA-Lipofectamine 3,000 mixture was incubated for $15 \mathrm{~min}$ at room temperature and used to transfect the HEK 293AAV cells. Medium exchange was performed at $6 \mathrm{~h}$ post transfection. The transfected HKE 293AAV cells were harvested and centrifuged at $48-60 \mathrm{~h}$ for further AAV clarification. 3) Cationic liposomes transfection: We synthesized cationic liposomes following similar synthetic procedure of neutral liposomes (Si et al., 2021) with modifications: mixing $7 \mu$ mole 1,2-dioleoyl-sn-glycero-3-phosphoethanolamine (DOPE), 7 mole 1,2-dioleoyl-3-trimethylammonium-propane (DOTAP) and $10 \mathrm{ml}$ of chloroform and evaporating at $60^{\circ} \mathrm{C}$ and $50 \mathrm{rpm}$ for $1 \mathrm{~h}$. The generated liposomes were analyzed using NanoSight, which showed concentration of $3.2 \times$ $10^{11}$ particles $/ \mathrm{ml}$ and mean size of $92.6 \pm 0.4 \mathrm{~nm}$. Total of $30 \mu \mathrm{g}$ three plasmids $(10 \mu \mathrm{g}$ each plasmid) were mixed with $900 \mu \mathrm{L}$ of cationic liposomes, incubated on ice for $30 \mathrm{~min}$, and mixed with Opti-MEM medium with volume ratio of $1: 1$. The HEK 293AAV cells in petri-dish were transfected with the liposomes-DNA complex and incubated for $48-60 \mathrm{~h}$ before AAV harvest.

\subsection{Adeno-Associated Viruses Production Using Suspension Culture}

The suspensive AAV production was performed in shaker flasks or spinner flasks. The Freestyle 293 medium was inoculated with HEK 293F cells at seeding VCD of $0.1-0.3 \times 10^{6}$ cells $/ \mathrm{ml}$ and incubated for 20-24 h before transfection. Different plasmid:cell ratios of 1.6, 3.3, and 6.6, and three transfection reagents of Polyethylenimine HCI (PEI) MAX, TurboFect and our synthesized liposomes were evaluated and compared in suspensive AAV production. The following formulation was designed for 30-ml HEK 293F culture. 1) PEI transfection: Total of $30 \mu \mathrm{g}$ plasmids $(10 \mu \mathrm{g}$ each plasmid) were mixed with $120 \mu \mathrm{L}$ of $1.6 \mathrm{mg} / \mathrm{ml}$ PEI MAX and incubated at $37^{\circ} \mathrm{C}$ for $10 \mathrm{~min}$, which was used to transfect HEK $293 \mathrm{~F}$ cells. 2) TurboFect transfection: The same formulation of TurboFect-DNA transfection complex as PEI was prepared for suspension transfection. 3) Cationic liposomes transfection: The same transfection reagent formulation as in adherent AAV production was used to transfect HEK 293F cells.

\subsection{Adeno-Associated Viruses Harvest and Clarification}

In the end of AAV production, cell pellets were collected with centrifugation of the culture broth at $1,000 \mathrm{~g}$ and $4^{\circ} \mathrm{C}$ for $10 \mathrm{~min}$. The cell pellets were re-suspended using lysis buffer $(50 \mathrm{mM}$ TrisCl, $150 \mathrm{mM} \mathrm{NaCl}, 2 \mathrm{mM} \mathrm{MgCl}$, $\mathrm{pH}$ 8.0) with volume of $1 / 30$ of production culture volume. Then cell lysis was processed through three cycles of freezing/thawing (30-min freezing in ethanol/dry ice and 15 -min in $37^{\circ} \mathrm{C}$ water bath thawing each cycle). The $50 \mathrm{U} / \mathrm{ml}$ benzonase and $5 \mu \mathrm{g} / \mathrm{ml}$ RNase A were added into AAV lysate and incubated in shaker at $37^{\circ} \mathrm{C}$ and $150 \mathrm{rpm}$ for $60 \mathrm{~min}$. Then $0.5 \%$ sodium deoxycholate was added to further treat the lysis solution for $30 \mathrm{~min}$. The AAV supernatant was collected after centrifugation at $3,000 \times g$ and $4^{\circ} \mathrm{C}$ for $20 \mathrm{~min}$, and filtered using 0.45 and $0.22 \mu \mathrm{m}$ PES membrane to remove cell debris.

\subsection{Adeno-Associated Viruses Titration and Storage}

To extract ssDNA from AAV, $1 \mu \mathrm{L}$ of $2000 \mathrm{U} / \mathrm{ml}$ DNase I (BioLabs), $2 \mu \mathrm{L}$ of $10 \mathrm{X}$ DNase I reaction buffer, $12 \mu \mathrm{L}$ of nuclease free water, and $5 \mu \mathrm{L}$ of AAV sample were added into a $0.2-\mathrm{ml}$ PCR tube. The mixture was incubated at $37^{\circ} \mathrm{C}$ for $30 \mathrm{~min}$ and followed with DNase I inactivation at $70^{\circ} \mathrm{C}$ for $10 \mathrm{~min}$. The sample was further digested with $1 \mu \mathrm{L}$ of $2 \mathrm{mg} / \mathrm{ml}$ Proteinase $\mathrm{K}$ by incubation at $50^{\circ} \mathrm{C}$ for $1 \mathrm{~h}$ and deactivation at $95^{\circ} \mathrm{C}$ for $20 \mathrm{~min}$. Finally, the extracted ssDNA was diluted by 10 folds with nuclease free water and titrated using RT-PCR with primers of NLuc forward: $5^{\prime}$-ATTGTCCTGAGCGGTGAAA-3', NLuc reverse: $\quad 5^{\prime}$-CACAGGGTACACCACCTTAAA- $3^{\prime}$, $\quad$ eYFP forward: $5^{\prime}$-GCACAAGCTGGAGTACAACTA-3', and eYFP reverse: $5^{\prime}$-TGTTGTGGCGGATCTTGAA-3'. The raw AAV or purified AAV was buffer exchanged in 1x PBS, 5\% Sorbitol, and $350 \mathrm{mmol} / \mathrm{L} \mathrm{NaCl}$, and stored at $-80^{\circ} \mathrm{C}$ for long term.

\subsection{In Vitro Transfection and In Vivo Infection Analysis}

The animal study conforms to the National Institutes of Health Guide for the Care and Use of Laboratory Animals published (Publication No. 85-23), with the approved animal protocol of IACUC-21949 by the Institutional Biosafety Committee at University of Alabama at Birmingham.

In in vitro evaluation, the MDA-MB-468 cancer cells were seeded in $2 \mathrm{ml}$ of complete DMEM/F12 medium in 6-well plate 


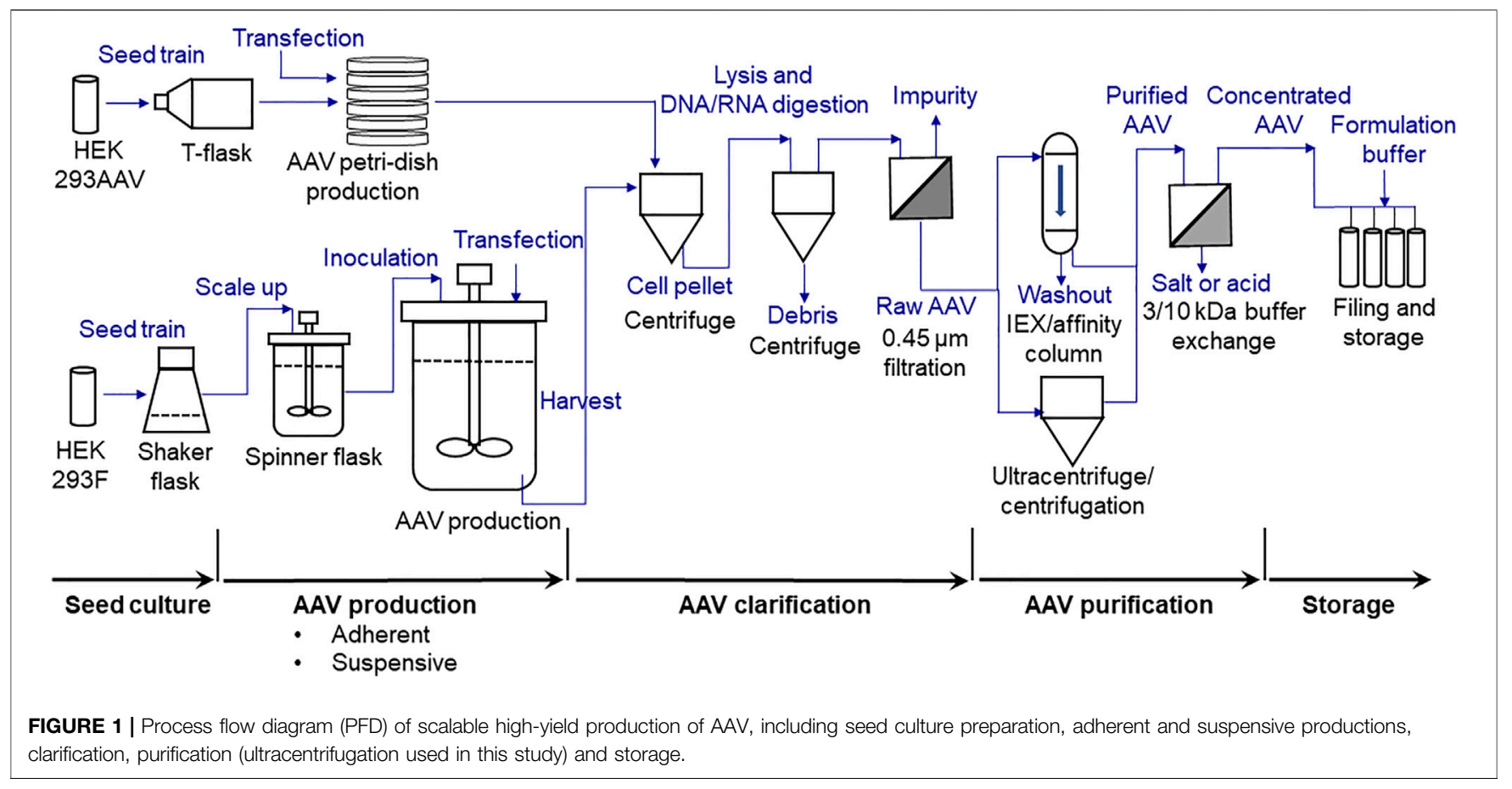

with seeding VCD of $0.05 \times 10^{6}$ cells $/ \mathrm{ml}$. After 24-h incubation, the cells were infected with the raw AAV carrying NLuc at multiplicity of infection (MOI) of 10,000 in triplication with mock infection with PBS as control. Two days after infection, the fresh growth medium containing $30 \mu \mathrm{M}$ of substate ViviRen was used to replace spent medium. The In Vivo Imaging System (IVIS) Lumina Series III (PerkinElmer, Waltham, MA, United Staes) was applied to take the bioluminescence images of infected cells at emission wavelength of $460 \mathrm{~nm}$.

To evaluate the in vivo infection capability of produced AAV, $5 \times 10^{6}$ human TNBC MDA-MB-468 cells were subcutaneously (s.c.) injected into the 6-week-old NSG (NOD scid gamma) female mice (Jackson Laboratory, Bar Harbor, ME) to establish xenograft model. Total of $1 \times 10^{10} \mathrm{gc}$ AAV was intravenously (i.v.) injected and mice were maintained for 7 days to allow NLuc expression, followed by i.p. injection of $37 \mu \mathrm{g}$ ViviRen substrate. The live-animal image was captured using IVIS system at excitation/emission wavelength of $660 / 710 \mathrm{~nm}$. The bioluminescence intensity was recorded with exposure time of $5 \mathrm{~s}$ to monitor peak excitation.

\subsection{Statistical Analysis}

The replication numbers $(n)$ used in this study was $>4$ and all experimental data were presented as mean \pm standard error of the mean (SEM). Two-tailed Student's $t$ tests were used to determine the probability of significance between groups and comparison was performed using a one-way ANOVA followed by post-hoc (Dunnett's) analysis. The statistical significance of ${ }^{* *} p$ value $<0.05$ was considered for all tests.

\section{RESULTS AND DISCUSSION}

\subsection{Adeno-Associated Viruses Biomanufacturing}

The overview of the developed AAV biomanufacturing process is detailed in Figure 1, including both adherent production, suspensive production, purification, and storage. In adherent operation mode, the HEK 293AAV cells were used to seed multiple petri-dishes for AAV production. The calcium solution that showed the highest transfection efficiency and AAV productivity was applied to deliver the three helper-free expression system plasmids, including the pAAV plasmid expressing NLuc reporter gene (Figure 2A) or eYFP reporter gene (Figure 2B), to HEK 293AAV cells. The key parameters that we identified in calcium transfection were the $\mathrm{pH}$ of transfection complex, medium exchange before transfection, and medium exchange post transfection. In suspensive operation mode, the HEK 293F cells were seeded in CD medium in shaker flasks or spinner flasks for AAV production. The synthesized cationic liposomes identified as the best transfection reagent was used to deliver plasmids to $293 \mathrm{~F}$ cells. The key parameters that we identified in suspensive production were the transfection cell density and ratio among liposomes, plasmid and cell number.

The cell pellets harvested in the end of AAV production were processed to release AAV through freezing/thawing in lysis buffer. The supplement of sodium deoxycholate, benzonase, and RNase A could further treat AAV lysis and remove DNA/ RNA impurities. The raw AAV supernatant post centrifugation was filtered using 0.45 and $0.22 \mu \mathrm{m}$ PES filters to remove cell debris. The well-developed iodixanol gradient ultracentrifugation could be used to purify AAV product, which could achieve high 


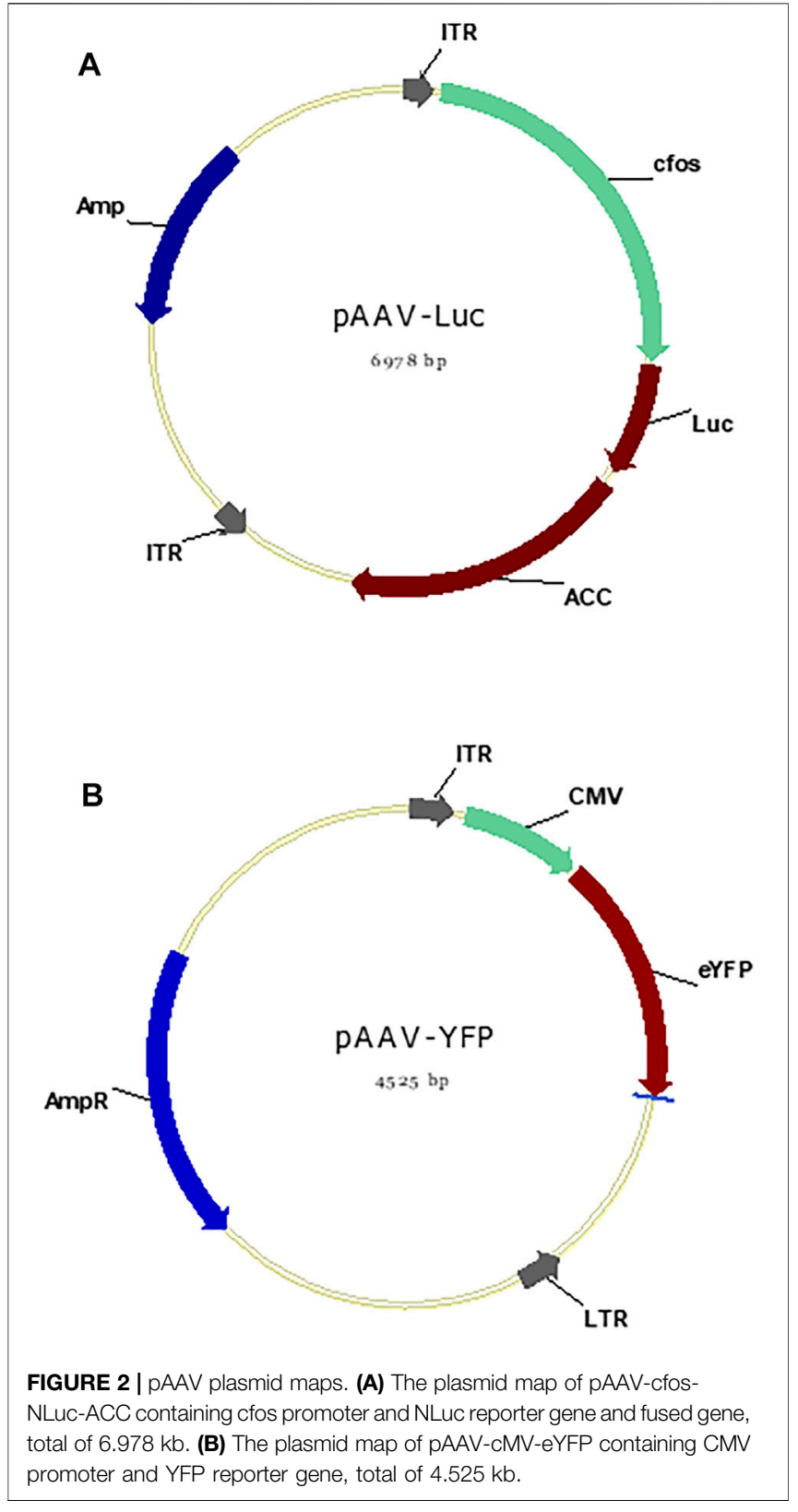

purity and recovery rate despite the low purification capacity and long processing procedure (Zolotukhin et al., 1999; Strobel et al., 2015). The ion-exchange chromatography column (Brument et al., 2002; Lock et al., 2012; Potter et al., 2014; Qu et al., 2015) or affinity chromatography column (Wu and Ataai, 2000; Grieger et al., 2006; Arakawa et al., 2007; Potter et al., 2014) can be used to purify some serotypes of AAVs. The buffer exchange and AAV concentration was performed using 3 or $10 \mathrm{kDa}$ MWCO concentrator. The purified AAV was stored at $-80^{\circ} \mathrm{C}$ freezer for long-term storage.

In this study, we focused on the process development and optimization of AAV-DJ/8 production and validation of the infection bioactivity. The purification and storage were also briefly tested and discussed.

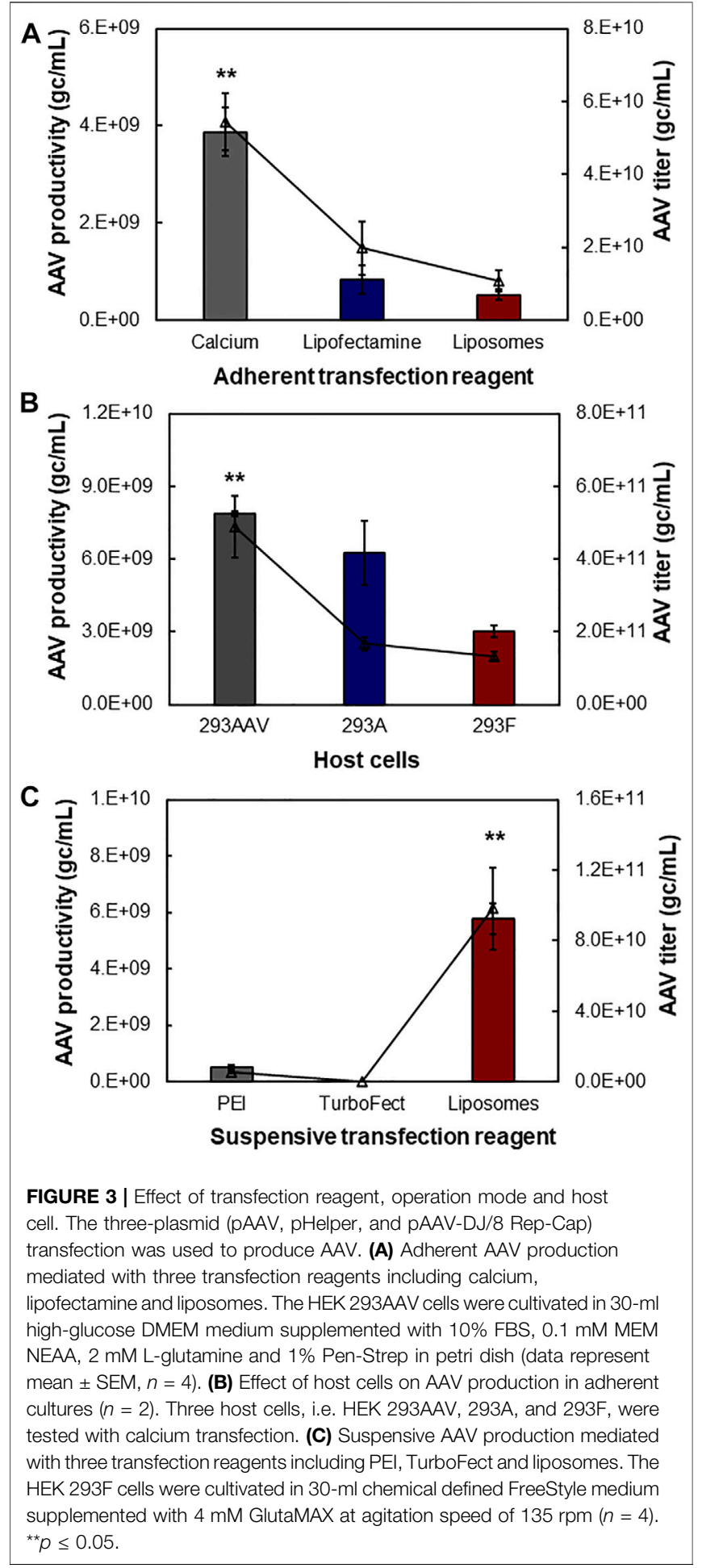

\subsection{Effect of Production Mode, Transfection Reagent and Host Cell}

During the AAV bioprocessing optimization, we first evaluated the effects of production mode (i.e., adherent and suspensive), transfection reagents and host cells on AAV packing and production. As described in Figure 3A, the calcium-facilitated 


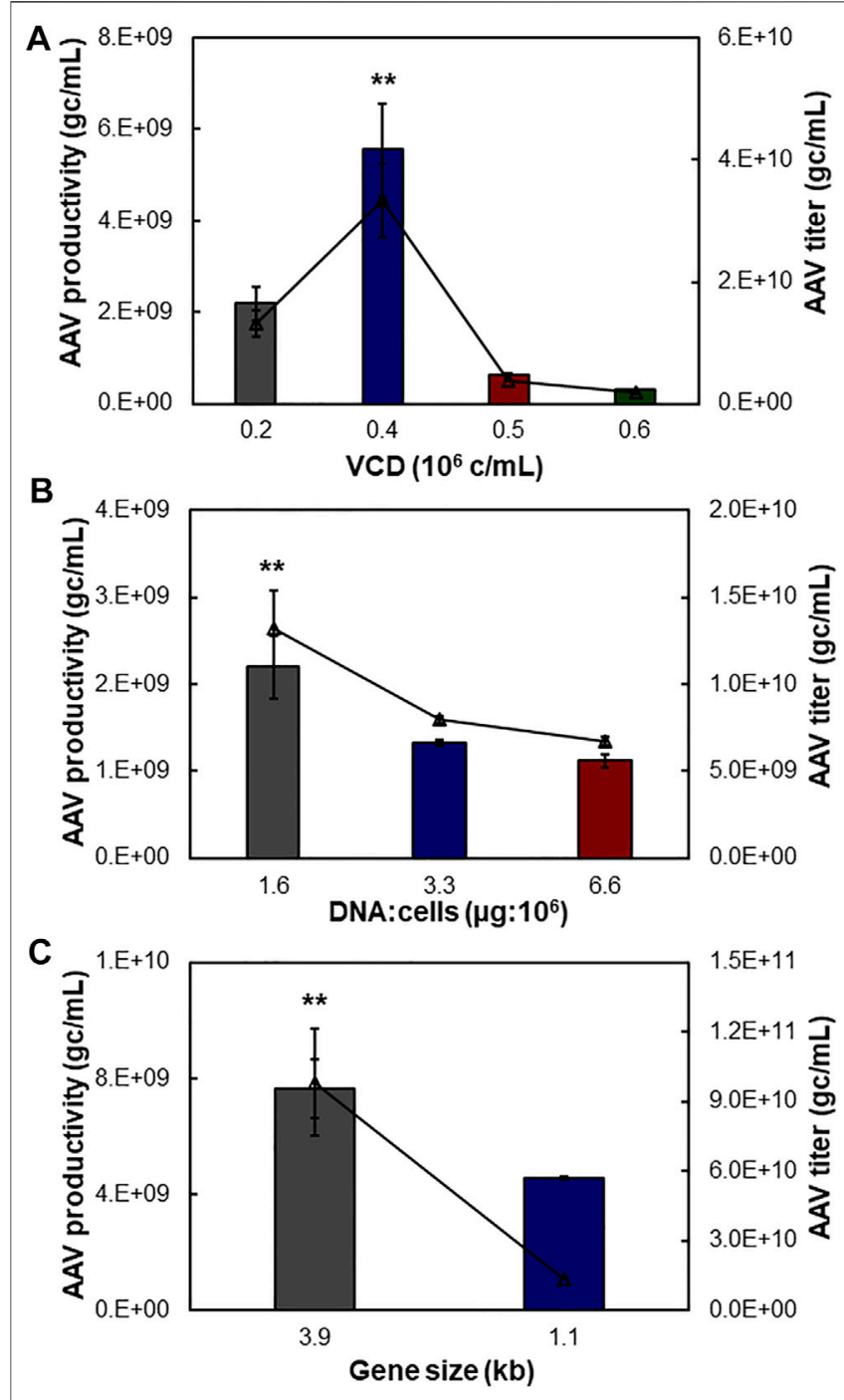

FIGURE 4 | Process optimization of suspensive AAV production. The pAAV plasmid carrying $3.9 \mathrm{~kb}$ of NLuc fused genes was used to transfect HEK 293F cells with duplication. (A) Effect of transfection viable cell density (VCD) on AAV production. (B) Effect of ratio of plasmid DNA $(\mu \mathrm{g})$ and host cell number $\left(10^{6}\right.$ cells). (C) Effect of gene size cloned in pAAV expression plasmid. Both 3.9 and $1.1 \mathrm{~kb}$ of insert genes were tested. ${ }^{* *} p \leq 0.05$.

transfection of pAAV-cfos-NLuc-ACC, pHelper, and pAAV-DJ/ 8 Rep-Cap plasmids generated the highest volumetric productivity of $3.87 \times 10^{9} \mathrm{gc} / \mathrm{ml}$ using HEK 293AAV cells in petri dishes. The transfections with lipofectamine 3,000 and inhouse synthesized cationic liposomes resulted in AAV productivity of $8.37 \times 10^{8} \mathrm{gc} / \mathrm{ml}$ and $5.29 \times 10^{8} \mathrm{gc} / \mathrm{ml}$, respectively. The titer of raw AAV lysis were $5.45 \times 10^{10} \mathrm{gc} /$ $\mathrm{ml}, 1.98 \times 10^{10} \mathrm{gc} / \mathrm{ml}$, and $1.09 \times 10^{10} \mathrm{gc} / \mathrm{ml}$ for these three transfection reagents. The comparison among three host cells showed that the HEK 293AAV cells had higher AAV productivity of $7.86 \times 10^{9} \mathrm{gc} / \mathrm{ml}$ and titer of $4.89 \times 10^{11} \mathrm{gc} / \mathrm{ml}$ than HEK $293 \mathrm{~A}$ with productivity of $6.25 \times 10^{9} \mathrm{gc} / \mathrm{ml}$ and titer of $1.67 \times 10^{11} \mathrm{gc} /$ $\mathrm{ml}$ and HEK $293 \mathrm{~F}$ cells with productivity of $3.01 \times 10^{9} \mathrm{gc} / \mathrm{ml}$ and titer of $1.34 \times 10^{11} \mathrm{gc} / \mathrm{ml}$ using calcium transfection in petri dish culture (Figure 3B). Three transfection reagents of PEI MAX, TurboFect and liposomes were investigated in suspensive AAV production. As shown in Figure 3C, the liposomes generated the highest AAV productivity of $5.78 \times 10^{9} \mathrm{gc} / \mathrm{ml}$ and titer of $9.84 \times$ $10^{10} \mathrm{gc} / \mathrm{ml}$ by HEK $293 \mathrm{~F}$ in shaker flasks. The PEI produced AAV with productivity of $5.38 \times 10^{8} \mathrm{gc} / \mathrm{ml}$ and titer of $5.38 \times 10^{9} \mathrm{gc} / \mathrm{ml}$, and TurboFect generated productivity of $1.70 \times 10^{8} \mathrm{gc} / \mathrm{ml}$ and titer of $2.83 \times 10^{7} \mathrm{gc} / \mathrm{ml}$.

This study showed that calcium had higher transfection efficiency than other reagents in adherent AAV production, but it's hard to use calcium to perform suspension transfection and medium exchange pre-and post-transfection. The cationic liposomes demonstrated high transfection efficiency in suspensive AAV production and the low cost of liposomes could significantly reduce the AAV production cost as compared to PEI and TurboFect. Moreover, the AAV productivity using HEK $293 \mathrm{~F}$ and liposomes was only $\sim 25 \%$ lower than that using HEK 293AAV and calcium. Therefore, the suspensive AAV production with HEK $293 \mathrm{~F}$ and cationic liposomes was performed to optimize AAV production.

\subsection{Transfection Optimization: Viable Cell Density, Ratio of DNA:Cell and Gene Size}

To further optimize the suspensive AAV production, we tested the effects of transfection cell density, ratio between plasmid DNA and transfected cells, and size of insert gene in the AAV-DJ/ 8 Helper Free Promoterless Expression System. In this study, the suspensive HEK 293F was transfected with synthesized liposomes. First, the transfection VCD of $0.4 \times 10^{6} \mathrm{cells} / \mathrm{ml}$ of HEK $293 \mathrm{~F}$ with pAAV carrying $3.9-\mathrm{kb}$ insert gene produced the highest productivity of $5.55 \times 10^{9} \mathrm{gc} / \mathrm{ml}$ and titer of $3.33 \times$ $10^{10} \mathrm{gc} / \mathrm{ml}$, which was significantly higher than that of VCD of $0.2,0.5$, and $0.6 \times 10^{6}$ cells $/ \mathrm{ml}$ with productivity of $0.29-2.20 \times$ $10^{9} \mathrm{gc} / \mathrm{ml}$ and titer of $0.18-1.32 \times 10^{10} \mathrm{gc} / \mathrm{ml}$ (Figure 4A). Second, different ratios of plasmid DNA and transfected cells were examined, including 1.6, 3.3, and $6.6 \mu \mathrm{g}: 10^{6}$ cells. The AAV production showed that ratio of 1.6 generated higher productivity $\left(2.20 \times 10^{9} \mathrm{gc} / \mathrm{ml}\right)$ and titer $\left(1.32 \times 10^{10} \mathrm{gc} / \mathrm{ml}\right)$ (Figure $\left.4 B\right)$. Third, the AAV production using pAAV carrying $3.9 \mathrm{~kb}$ of insert gene was higher than that using pAAV carrying $1.1 \mathrm{~kb}$ of insert, i.e., productivity of $7.64 \mathrm{vs} .4 .56 \times 10^{9} \mathrm{gc} / \mathrm{ml}$ and titer of $9.84 \mathrm{vs}$. $1.37 \times 10^{10} \mathrm{gc} / \mathrm{ml}$ (Figure $4 \mathrm{C}$ ). The maximum insert of AAV-DJ/ 8 expression system is $3.9 \mathrm{~kb}$, including promoter and gene of interest, so we tested a large insert cfos-NLuc-ACC with size of $3.9 \mathrm{~kb}$ and small insert CMV-eYFP with size of $1.1 \mathrm{~kb}$ in this study.

HEK $293 \mathrm{~F}$ cells have been widely used to transiently produce antibody or other recombinant protein. Literature has reported that the plasmid transfection and protein expression level are affected by the transfection VCD and ratio of plasmid and cells (Grieger et al., 2016). This study showed that the transfection cell density and plasmid amount can be optimized to improve the suspensive AAV production. Interestingly, we found that the size of insert gene had no obvious correlation to AAV production in suspensive culture. The identified optimal transfection conditions, i.e. transfection VCD of $0.4 \times 10^{6}$ cells $/ \mathrm{ml}$, plasmid 
TABLE 1 | Summary of tested AAV production parameters.

\begin{tabular}{|c|c|c|c|c|c|c|c|}
\hline $\begin{array}{l}\text { Production } \\
\text { mode }\end{array}$ & $\begin{array}{l}\text { Host } \\
\text { cells }\end{array}$ & $\begin{array}{l}\text { Transfection } \\
\text { reagent }\end{array}$ & $\begin{array}{c}\text { Transfection VCD } \\
\left(\times 10^{6} \mathrm{c} / \mathrm{mL}\right)\end{array}$ & $\begin{array}{l}\text { DNA:cell } \\
\left(\mu \mathrm{g}: 10^{6}\right)\end{array}$ & $\begin{array}{c}\text { Gene } \\
\text { size (kb) }\end{array}$ & $\begin{array}{c}\text { Container and } \\
\text { scale }\end{array}$ & $\begin{array}{l}\text { AAV volumetric } \\
\text { productivity } \\
\text { (gc/ml) }\end{array}$ \\
\hline \multirow[t]{5}{*}{ Adherent } & 293AAV & Calcium & 0.4 & 3.3 & 3.9 & Petri dish, $30 \mathrm{ml}$ & $3.87-7.86 \pm 0.54 \times 10^{9}$ \\
\hline & & Lipofectamine & 0.4 & 3.3 & 3.9 & Petri dish, $30 \mathrm{ml}$ & $8.37 \pm 3.02 \times 10^{8}$ \\
\hline & & Liposomes & 0.4 & 3.3 & 3.9 & Petri dish, $30 \mathrm{ml}$ & $5.29 \pm 1.02 \times 10^{8}$ \\
\hline & $293 \mathrm{~A}$ & Calcium & 0.4 & 3.3 & 3.9 & Petri dish, $30 \mathrm{ml}$ & $6.25 \pm 1.31 \times 10^{9}$ \\
\hline & $293 F$ & Calcium & 0.4 & 3.3 & 3.9 & Petri dish, $30 \mathrm{ml}$ & $3.01 \pm 0.25 \times 10^{9}$ \\
\hline \multirow[t]{14}{*}{ Suspensive } & $293 F$ & PEI & 0.4 & 3.3 & 3.9 & Shaker flask, $30 \mathrm{ml}$ & $5.38 \pm 0.65 \times 10^{8}$ \\
\hline & $293 F$ & TurboFect & 0.4 & 3.3 & 3.9 & Shaker flask, $30 \mathrm{ml}$ & $2.83 \pm 0.43 \times 10^{7}$ \\
\hline & $293 F$ & Liposomes & 0.4 & 3.3 & 3.9 & Shaker flask, $30 \mathrm{ml}$ & $5.78 \pm 0.56 \times 10^{9}$ \\
\hline & $293 F$ & Liposomes & 0.2 & 1.6 & 3.9 & Shaker flask, $30 \mathrm{ml}$ & $2.20 \pm 0.36 \times 10^{9}$ \\
\hline & $293 F$ & Liposomes & 0.4 & 1.6 & 3.9 & Shaker flask, $30 \mathrm{ml}$ & $5.55 \pm 1.01 \times 10^{9}$ \\
\hline & $293 F$ & Liposomes & 0.5 & 1.6 & 3.9 & Shaker flask, 30 ml & $6.46 \pm 0.22 \times 10^{8}$ \\
\hline & $293 F$ & Liposomes & 0.6 & 1.6 & 3.9 & Shaker flask, $30 \mathrm{ml}$ & $2.98 \pm 0.18 \times 10^{8}$ \\
\hline & $293 F$ & Liposomes & 0.4 & 1.6 & 3.9 & Shaker flask, $30 \mathrm{ml}$ & $2.20 \pm 0.36 \times 10^{9}$ \\
\hline & $293 F$ & Liposomes & 0.4 & 3.3 & 3.9 & Shaker flask, $30 \mathrm{ml}$ & $1.33 \pm 0.03 \times 10^{9}$ \\
\hline & $293 F$ & Liposomes & 0.4 & 6.6 & 3.9 & Shaker flask, $30 \mathrm{ml}$ & $1.12 \pm 0.08 \times 10^{9}$ \\
\hline & $293 F$ & Liposomes & 0.4 & 1.6 & 3.9 & Shaker flask, $30 \mathrm{ml}$ & $7.64 \pm 0.99 \times 10^{9}$ \\
\hline & $293 F$ & Liposomes & 0.4 & 1.6 & 1.1 & Shaker flask, $30 \mathrm{ml}$ & $4.56 \pm 0.06 \times 10^{9}$ \\
\hline & $293 F$ & Liposomes & 0.4 & 1.6 & 3.9 & $\begin{array}{l}\text { Shaker flask, } \\
240 \mathrm{ml}\end{array}$ & $5.04 \pm 0.63 \times 10^{9}$ \\
\hline & $293 F$ & Liposomes & 0.4 & 1.6 & 3.9 & $\begin{array}{l}\text { Spinner flask, } \\
450 \mathrm{ml}\end{array}$ & $4.99 \pm 0.82 \times 10^{9}$ \\
\hline
\end{tabular}

Note: All data are presented as mean \pm standard error of the mean (SEM).

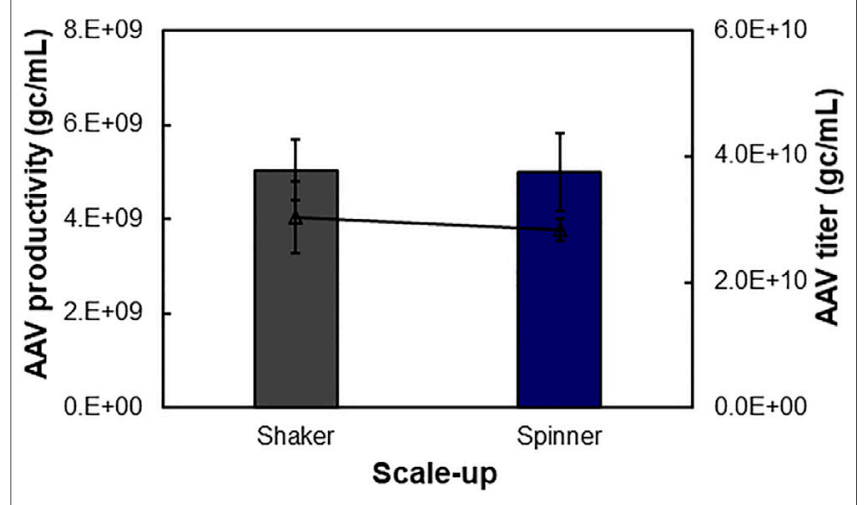

FIGURE 5 | Scalability of suspensive AAV production process. AAV production can be scaled up from 30 to $450 \mathrm{ml}$ in shaker flasks at $37^{\circ} \mathrm{C}$ and agitation $100 \mathrm{rpm}$ and spinner flasks at $37^{\circ} \mathrm{C}$ and agitation $70 \mathrm{rpm}$.

and HEK 293F cell ratio of 1.6, and synthesized cationic liposomes, were used in suspensive AAV production process.

\subsection{Process Scalability}

The scalability of our developed suspensive AAV production process was evaluated in both shaker flask and spinner flask, which showed consistent AAV productivity. Specifically, the identified process parameters in 30 - $\mathrm{ml}$ shaker flask suspension production (Table 1), i.e. transfection VCD of $0.4 \times 10^{6}$ cells/ $\mathrm{ml}$ of HEK $293 \mathrm{~F}$ cells, liposomes as transfection reagent of 6.9kb pAAV-Luc, and DNA:cells ratio of $1.6 \mu \mathrm{g}: 106$ cells, were applied in the scalability evaluation in $240-\mathrm{ml}$ of production culture in shaker flask at $37^{\circ} \mathrm{C}$ and agitation $100 \mathrm{rpm}$ and 450 - $\mathrm{ml}$ production culture in spinner flask at $37^{\circ} \mathrm{C}$ and agitation $70 \mathrm{rpm}$. As presented in Figure 5, the 240-ml production culture in $1-\mathrm{L}$ shaker flask and $450-\mathrm{ml}$ culture in 1-L spinner flask produced similar level of AAV with volumetric productivity of $5.04 \times 10^{9} \mathrm{gc} / \mathrm{ml}$ and $4.99 \times$ $10^{9} \mathrm{gc} / \mathrm{ml}$ and titer of $3.02 \times 10^{10} \mathrm{gc} / \mathrm{ml}$ and $2.84 \times 10^{10} \mathrm{gc} /$ $\mathrm{ml}$, respectively. During the liposomes-mediated plasmid transfection in shaker and spinner flasks, the cultures were kept in static status for half hour after adding transfection complex. Medium exchange is not necessary pre- and posttransfections. The successful scale-up of AAV production in spinner flask indicated the possibility to produce large-scale AAV in stirred-tank bioreactor.

\subsection{Formulation Buffer and Storage Condition}

In this study, the raw or purified AAV was concentrated and exchanged to formulation buffer (1x PBS, 5\% sorbitol, $350 \mathrm{mmol} /$ $\mathrm{L} \mathrm{NaCl}$ ). It is found that AAV is stable with this storage condition and the functional titer change is $<5 \%$ between pre-freezing and post-thawing.

\subsection{Infection Bioactivity}

In addition to genome copy-based titration, it's very important to evaluate the bilogical activity of AAV carrying the NLuc reporter gene. In this study, we transfected the TNBC MDA-MB-468 cells using AAV in 6-well plate. As shown in Figure 6A, the high-level expression of NLuc gene was detected in the cancer cells with IVIS imaging, but no bioluminecent signal in the cells with mock infection (i.e., no AAV). This result confirmed the in vitro transfection and bioactivity of the produced AAV. The kinetic 

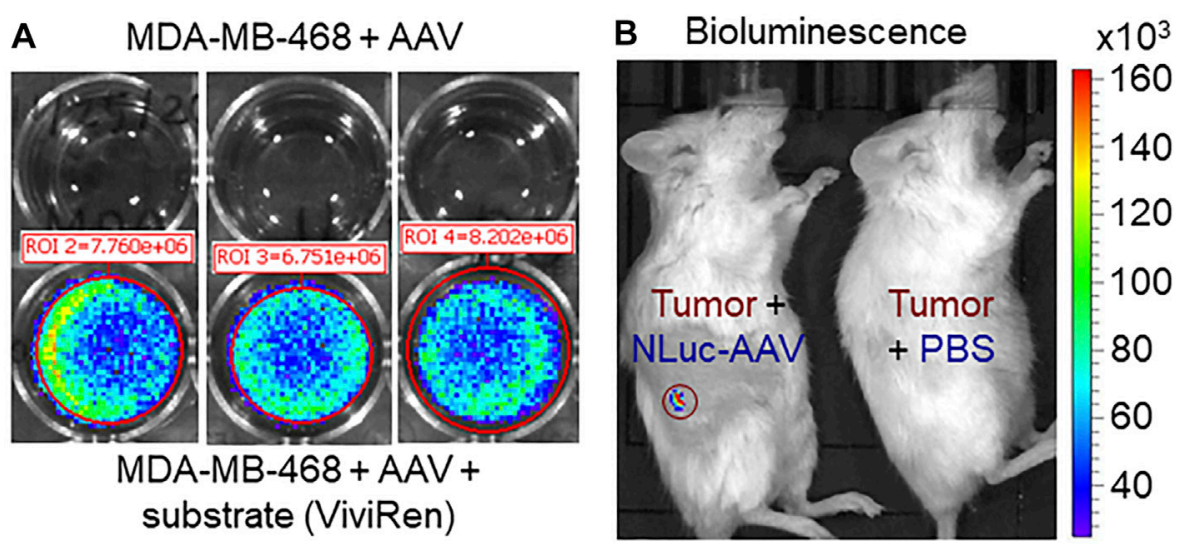

FIGURE 6 | Evaluation of AAV transfection/infection capability. (A) In vitro transfection and gene expression of AAV in TNBC MDA-MB-468 cells. Multiplicity of infection (MOI): 10,000. Live-cell In Vivo Imaging System (IVIS) image was taken 3 days after transfection. (B) In vivo infection and gene expression of AAV in TNBC xenograft model. Live-animal IVIS image was taken 7 days post AAV injection.

profile of in vivo NLuc bioluminecence, which was excited at wavelength of $470 \mathrm{~nm}$, demosntrated the peak signal at $\sim 15 \mathrm{~min}$ post substrate induction followed with signal reduction by $67 \%$ wuthin $60 \mathrm{~min}$. We further tested the in vivo infection efficiency by administrating AAV into the TNBC MDA-MB-468 xengraft models via tail vein. As described in Figure 6B, we detected the functional expression of NLuc gene in TNBC xenograft, which demonstrated the effective in vivo infection and gene expression that was delivered by AAV. Moreover, the application of cancerspecific promoter cfos resulted in gene expression in tumor xenograft. To overcome the challenge of possible low resolution of live-animal IVIS imaging, we will further validate the AAV biodistribution through RT-PCR analysis of the important organs to detect the mRNA level of delivered gene in future.

\subsection{Challenges in Adeno-Associated Viruses Biomanufacturing and Future Work}

This study compared and optimized both adherent production and suspensive production of AAV as summarized in Table 1. The results showed that these two operation modes could generate AAV with similar productivity and titer, which is doable for small-scale production. However, the large-amount AAV needs scalable suspensive production in stirred-tank container or bioreactor with optimal transfection conditions. For example, the agitation speed could affect the transfection efficiency significantly and might need optimization after adding transfection complex. The inhouse synthesized cationic liposomes have size distribution of $92.6 \pm 0.4 \mathrm{~nm}$ and titer of $3.2 \times 10^{11} \mathrm{particles} / \mathrm{ml}$. The particle size of the cationic liposomes could be further optimized in order to improve the suspensive transfection efficiency. Although the AAV-DJ/8 with an engineered capsid to achieve high in vivo infection efficiency was used as model system, the developed bioprocess could be used to generate different serotypes.

\subsection{Purification Challenges and Future Work}

This study aimed to optimize the AAV production bioprocessing, so we did not focus on purification strategies. However, we performed a quick test and evaluation of two chromatography purification methods following published protocols to purify AAV-DJ/8. The ion-exchange purification using liquid chromatography system (Bio-Rad, Hercules, CA, United States) equipped with Cytiva HiTrap ${ }^{\mathrm{TM}}$ Q Sepharose XL IEX column (Cytiva, Marlborough, MA, United States) (Brument et al., 2002; Lock et al., 2012; Potter et al., 2014; Qu et al., 2015) was performed, but the recovery rate was lower than $10 \%$ and the purity was low. The affinity purification with Cytiva HiTrap ${ }^{\mathrm{TM}}$ AVB Sepharose column (Wu and Ataai, 2000; Grieger et al., 2006; Arakawa et al., 2007; Potter et al., 2014) was also tested, and the recovery rate was less than $1 \%$ or close to $0 \%$. The failure to use AVB column to isolate AAV-DJ/8 was also reported by Andari and Grimm (El Andari and Grimm, 2021) and Nass et al. (Nass et al., 2018) due to the serotypes evolution. The traditional iodixanol gradient ultracentrifugation with Beckman Coulter L-100K ultracentrifuge (Beckman Coulter, Brea, CA) (Zolotukhin et al., 1999; Strobel et al., 2015) achieved the highest recovery rate and purity although the operation took a long time and was hard to scale up. We will further develop and optimize the chromatography-based AAV purification protocol in future study.

\section{CONCLUSION}

In this study, we developed a scalable robust suspensive AAV production process. The host cells, transfection reagents, transfection conditions (viable cell density, plasmid DNA and gene size), and culture containers were evaluated to determine the optimal process parameters. Furthermore, the scalability and robustness of the developed biomanufacturing was confirmed in both shaker flask and spinner flask. The produced AAV 
showed high transfection/infection capability in cancer cell lines and tumor xenograft models. Despite the promising results, we need to further optimize the liposomes transfection of suspensive cells and also develop an efficient AAV purification process for large-scale suspensive AAV production.

\section{DATA AVAILABILITY STATEMENT}

The original contributions presented in the study are included in the article/supplementary material, further inquiries can be directed to the corresponding author.

\section{ETHICS STATEMENT}

The animal study was reviewed and approved by the animal study conforms to the National Institutes of Health Guide for the Care and Use of Laboratory Animals published (Publication No. 8523), with the approved animal protocol of IACUC-21949 by the

\section{REFERENCES}

Arakawa, T., Ejima, D., Tsumoto, K., Ishibashi, M., and Tokunaga, M. (2007). Improved Performance of Column Chromatography by Arginine: Dye-Affinity Chromatography. Protein Expr. Purif. 52, 410-414. doi:10.1016/j.pep.2006. 10.005

Blessing, D., Vachey, G., Pythoud, C., Rey, M., Padrun, V., Wurm, F. M., et al. (2019). Scalable Production of AAV Vectors in Orbitally Shaken HEK293 Cells. Mol. Ther. - Methods Clin. Development 13, 14-26. doi:10.1016/j.omtm.2018. 11.004

Brument, N., Morenweiser, R., Blouin, V., Toublanc, E., Raimbaud, I., Chérel, Y., et al. (2002). A Versatile and Scalable Two-step Ion-Exchange Chromatography Process for the Purification of Recombinant AdenoAssociated Virus Serotypes-2 and -5. Mol. Ther. 6, 678-686. doi:10. $1006 / \mathrm{mthe} .2002 .0719$

Büning, H., and Srivastava, A. (2019). Capsid Modifications for Targeting and Improving the Efficacy of AAV Vectors. Mol. Ther. - Methods Clin. Development 12, 248-265. doi:10.1016/j.omtm.2019.01.008

Carter, B. J. (2005). Adeno-associated Virus Vectors in Clinical Trials. Hum. Gene Ther. 16, 541-550. doi:10.1089/hum.2005.16.541

Chahal, P. S., Schulze, E., Tran, R., Montes, J., and Kamen, A. A. (2014). Production of Adeno-Associated Virus (AAV) Serotypes by Transient Transfection of HEK293 Cell Suspension Cultures for Gene Delivery. J. Virol. Methods 196, 163-173. doi:10.1016/j.jviromet.2013.10.038

Crosson, S. M., Dib, P., Smith, J. K., and Zolotukhin, S. (2018). Helper-free Production of Laboratory Grade AAV and Purification by Iodixanol Density Gradient Centrifugation. Mol. Ther. - Methods Clin. Development 10, 1-7. doi:10.1016/j.omtm.2018.05.001

El Andari, J., and Grimm, D. (2021). Production, Processing, and Characterization of Synthetic AAV Gene Therapy Vectors. Biotechnol. J. 16, e2000025. doi:10. 1002/biot.202000025

Ernst, P., Xu, N., Qu, J., Chen, H., Goldberg, M. S., Darley-Usmar, V., et al. (2019). Precisely Control Mitochondria with Light to Manipulate Cell Fate Decision. Biophysical J. 117, 631-645. doi:10.1016/j.bpj.2019.06.038

Govorunova, E. G., Sineshchekov, O. A., Li, H., Janz, R., and Spudich, J. L. (2013). Characterization of a Highly Efficient Blue-Shifted Channelrhodopsin from the marine Alga Platymonas Subcordiformis. J. Biol. Chem. 288, 29911-29922. doi:10.1074/jbc.m113.505495

Grieger, J. C., Choi, V. W., and Samulski, R. J. (2006). Production and Characterization of Adeno-Associated Viral Vectors. Nat. Protoc. 1, 1412-1428. doi:10.1038/nprot.2006.207
Institutional Biosafety Committee at University of Alabama at Birmingham.

\section{AUTHOR CONTRIBUTIONS}

All authors listed have made a substantial, direct, and intellectual contribution to the work and approved it for publication.

\section{FUNDING}

This work was supported by DoD BCRP W81XWH2110066 (XL) and W81XWH2110067 (LZ).

\section{ACKNOWLEDGMENTS}

The authors would like to thank the Small Animal Imaging Facility at University of Alabama at Birmingham (UAB) for the IVIS imaging.

Grieger, J. C., Soltys, S. M., and Samulski, R. J. (2016). Production of Recombinan Adeno-Associated Virus Vectors Using Suspension HEK293 Cells and Continuous Harvest of Vector from the Culture Media for GMP FIX and FLT1 Clinical Vector. Mol. Ther. 24, 287-297. doi:10.1038/mt.2015.187

Hacker, U. T., Bentler, M., Kaniowska, D., Morgan, M., and Büning, H. (2020). Towards Clinical Implementation of Adeno-Associated Virus (AAV) Vectors for Cancer Gene Therapy: Current Status and Future Perspectives. Cancers (Basel) 12, 1889-1918. doi:10.3390/cancers12071889

Koerber, J. T., Jang, J.-H., and Schaffer, D. V. (2008). DNA Shuffling of AdenoAssociated Virus Yields Functionally Diverse Viral Progeny. Mol. Ther. 16, 1703-1709. doi:10.1038/mt.2008.167

Ledley, F. D., McNamee, L. M., Uzdil, V., and Morgan, I. W. (2014). Why Commercialization of Gene Therapy Stalled; Examining the Life Cycles of Gene Therapy Technologies. Gene Ther. 21, 188-194. doi:10.1038/gt.2013.72

Li, W., Asokan, A., Wu, Z., Van Dyke, T., DiPrimio, N., Johnson, J. S., et al. (2008). Engineering and Selection of Shuffled AAV Genomes: A New Strategy for Producing Targeted Biological Nanoparticles. Mol. Ther. 16, 1252-1260. doi:10. 1038/mt.2008.100

Lock, M., Alvira, M. R., and Wilson, J. M. (2012). Analysis of Particle Content of Recombinant Adeno-Associated Virus Serotype 8 Vectors by Ion-Exchange Chromatography. Hum. Gene Ther. Methods 23, 56-64. doi:10.1089/hgtb. 2011.217

Mietzsch, M., Grasse, S., Zurawski, C., Weger, S., Bennett, A., Agbandje-McKenna, M., et al. (2014). OneBac: Platform for Scalable and High-Titer Production of Adeno-Associated Virus Serotype 1-12 Vectors for Gene Therapy. Hum. Gene Ther. 25, 212-222. doi:10.1089/hum.2013.184

Nass, S. A., Mattingly, M. A., Woodcock, D. A., Burnham, B. L., Ardinger, J. A., Osmond, S. E., et al. (2018). Universal Method for the Purification of Recombinant AAV Vectors of Differing Serotypes. Mol. Ther. - Methods Clin. Development 9, 33-46. doi:10.1016/j.omtm.2017.12.004

Negrini, M., Wang, G., Heuer, A., Björklund, T., and Davidsson, M. (2020). AAV Production Everywhere: A Simple, Fast, and Reliable Protocol for In-House AAV Vector Production Based on Chloroform Extraction. Curr. Protoc. Neurosci. 93, e103. doi:10.1002/cpns.103

Nguyen, T. N. T., Sha, S., Hong, M. S., Maloney, A. J., Barone, P. W., Neufeld, C., et al. (2021). Mechanistic Model for Production of Recombinant AdenoAssociated Virus via Triple Transfection of HEK293 Cells. Mol. Ther. Methods Clin. Development 21, 642-655. doi:10.1016/j.omtm.2021.04.006

Potter, M., Lins, B., Mietzsch, M., Heilbronn, R., Van Vliet, K., Chipman, P., et al. (2014). A Simplified Purification Protocol for Recombinant Adeno-Associated Virus Vectors. Mol. Ther. - Methods Clin. Development 1, 14034. doi:10.1038/ mtm.2014.34 
Qu, W., Wang, M., Wu, Y., and Xu, R. (2015). Scalable Downstream Strategies for Purification of Recombinant Adeno- Associated Virus Vectors in Light of the Properties. Cpb 16, 684-695. doi:10.2174/1389201016666150505122228

Senís, E., Fatouros, C., Grosse, S., Wiedtke, E., Niopek, D., Mueller, A.-K., et al. (2014). CRISPR/Cas9-mediated Genome Engineering: an Adeno-Associated Viral (AAV) Vector Toolbox. Biotechnol. J. 9, 1402-1412. doi:10.1002/biot. 201400046

Si, Y., Zhang, Y., Ngo, H. G., Guan, J. S., Chen, K., Wang, Q., et al. (2021). Targeted Liposomal Chemotherapies to Treat Triple-Negative Breast Cancer. Cancers (Basel) 13. doi:10.3390/cancers 13153749

Strobel, B., Miller, F. D., Rist, W., and Lamla, T. (2015). Comparative Analysis of Cesium Chloride- and Iodixanol-Based Purification of Recombinant AdenoAssociated Viral Vectors for Preclinical Applications. Hum. Gene Ther. Methods 26, 147-157. doi:10.1089/hgtb.2015.051

Urabe, M., Nakakura, T., Xin, K.-Q., Obara, Y., Mizukami, H., Kume, A., et al. (2006). Scalable Generation of High-Titer Recombinant Adeno-Associated Virus Type 5 in Insect Cells. J. Virol. 80, 1874-1885. doi:10.1128/jvi.80.4. 1874-1885.2006

van der Loo, J. C. M., and Wright, J. F. (2016). Progress and Challenges in Viral Vector Manufacturing. Hum. Mol. Genet. 25, R42-R52. doi:10.1093/hmg/ ddv451

Wright, J. F. (2008). Manufacturing and Characterizing AAV-Based Vectors for Use in Clinical Studies. Gene Ther. 15, 840-848. doi:10.1038/gt.2008.65

Wu, N., and Ataai, M. M. (2000). Production of Viral Vectors for Gene Therapy Applications. Curr. Opin. Biotechnol. 11, 205-208. doi:10.1016/s0958-1669(00) 00080-x
Zhao, H., Lee, K.-J., Daris, M., Lin, Y., Wolfe, T., Sheng, J., et al. (2020). Creation of a High-Yield AAV Vector Production Platform in Suspension Cells Using a Design-Of-Experiment Approach. Mol. Ther. - Methods Clin. Development 18, 312-320. doi:10.1016/j.omtm.2020.06.004

Zolotukhin, S., Byrne, B. J., Mason, E., Zolotukhin, I., Potter, M., Chesnut, K., et al. (1999). Recombinant Adeno-Associated Virus Purification Using Novel Methods Improves Infectious Titer and Yield. Gene Ther. 6, 973-985. doi:10.1038/sj.gt.3300938

Conflict of Interest: The authors declare that the research was conducted in the absence of any commercial or financial relationships that could be construed as a potential conflict of interest.

Publisher's Note: All claims expressed in this article are solely those of the authors and do not necessarily represent those of their affiliated organizations, or those of the publisher, the editors and the reviewers. Any product that may be evaluated in this article, or claim that may be made by its manufacturer, is not guaranteed or endorsed by the publisher.

Copyright (C) 2022 Guan, Chen, Si, Kim, Zhou, Kim, Zhou and Liu. This is an openaccess article distributed under the terms of the Creative Commons Attribution License (CC BY). The use, distribution or reproduction in other forums is permitted, provided the original author(s) and the copyright owner(s) are credited and that the original publication in this journal is cited, in accordance with accepted academic practice. No use, distribution or reproduction is permitted which does not comply with these terms. 